\title{
A Discussion of FinTech's impacts on the Market Structure of China's Banking and the regulation problems
}

\section{Hanying QI}

Ph.D., Department of Economics, Central University of Finance and Economics, Beijing, China.

\section{fly7878@126.com}

\begin{abstract}
FinTech has profoundly changed the products, models and institutions of the banking industry. It has also brought many problems while improving banking's performance, which poses great challenge to the banking industry. This paper analyzes the impact of Fintech on China's banking industry and its regulation problems from the perspective of market structure. FinTech has a "head effect" and a "long tail effect" on the market concentration of the banking industry. In terms of market barriers, FinTech has lowered some technical barriers and information barriers and resulting in new access barriers; In terms of finance functions, FinTech has reduced the horizontal differentiation of banking products and strengthened the vertical differentiation of products. Financial supervision should fully consider the changes in the market structure of banking industry and build a coordination mechanism for the competition policy and risk supervision of the banking industry.
\end{abstract}

Keywords - FinTech, market structure, banking industry, banking regulation

\section{INTRODUCTION}

The combination of finance and information technology has a long history. At the beginning of the telephone generation in the 1930s, information technology began to play an increasingly important role in the financial services industry. It can be said that the emergence of "FinTech" is a new in the history of the combination of finance and technology. stage. The term "FinTech" (FinTech, the abbreviation of Financial Technology, all of which uses the Chinese translation "FinTech" below) was first proposed by Bettinger in 1972 to represent the combination of banking and modern management science and computers (Bettinger, 1972), but has not received widespread attention from the practical and academic circles. Beginning in the 1990s, "FinTech" became the abbreviation of Financial Services Technology Consortium. After the 2008 financial crisis, FinTech began to receive more attention (Arner, Barberis and Buckley, 2017), which became popular in 2010 (Saksonova and Kuzmina-Merlino, 2017) and was widely used in 2014. The content, form, and impact of FinTech are receiving a lot of attention (Arner, Barberis and Buckley,
2016). With regard to the scope of FinTech, scholars have different definitions from different dimensions. Among them, technical attributes, financial functions, and physical institutions are the three mainstream dimensions (Alt, Beck and Smits, 2018; Gai, Qiu and Sun, 2018).

The combination of finance and information technology can also be divided into three stages, drawing on Arna's (2016) division of the development stage of FinTech. The first stage is the FinTech1.0 era of 1866-1967, that is, the application of analog technology. The financial services industry is mainly concerned with the transmission of information and transactions; the second is the FinTech2.0 era of 1967-2008, which is the stage of digitization of the financial industry due to the development of digital technology and communication; the third is since 2008 In the FinTech 3.0 era, the main performance is that new startups and technology companies use information technological innovation to propose financial solutions, provide financial services to enterprises and individuals, and compete with traditional financial institutions (Arner, Barberis and Buckley, 2016). The impact of current 
FinTech on the banking industry is an important manifestation of the third phase of FinTech. At this stage, FinTech not only has internal reform impact on traditional banking institutions, but also promotes the transformation of the banking industry from the periphery, and its intensity and degree are stronger than ever before. These issues have become the focus of financial regulatory reform. Today China is gradually building a functional financial regulatory framework based on prudential regulation and behavioral supervision. Among them, "behavioral supervision" has received more and more attention. How to establish a fair competitive market environment by monitoring the behavior of banking market participants is also an important issue of behavior regulation. From the perspective of industrial organization theory, market structure is a state manifestation of market relations among market entities. It is influenced by market behavior and performance, and also affects the behavior and performance of future market players. Therefore, based on the development of the third stage of FinTech, this paper cuts into the analytical framework of FinTech affecting the banking industry from the perspective of market structure, so as to get a glimpse of the current status of the banking market under FinTech and its corresponding supervision.

\section{THE IMPACT OF FINTECH ON CHINA'S BANKING INDUSTRY}

There are two main paths for the impact of FinTech on China's banking industry. First, technological and financial innovation factors in FinTech promote innovation and reform the banking industry internally; second, FinTech companies promote the development of the banking industry by competing with traditional banking institutions externally. From the perspective of market structure, FinTech has changed the market concentration, entry barriers and production differentiation of the banking market through the above two paths. As shown in the figure 1 , firstly the banking market concentration can be decreased by the entrance of FinTech enterprises and the technological and functional innovation factors of FinTech play a supporting role in this mechanism; the change in barriers to entry in the banking industry is mainly due to the technological aspects of FinTech which has changed the way banks produce method. Productions differentiation is mainly affected by the differences in financial functions, while technology and institutions are mainly support factors for production differentiation. The market structure of the banking industry is closely related to financial stability and market competition. From this point of view, this paper will provide empirical evidence for the formulation of banking regulatory policies.

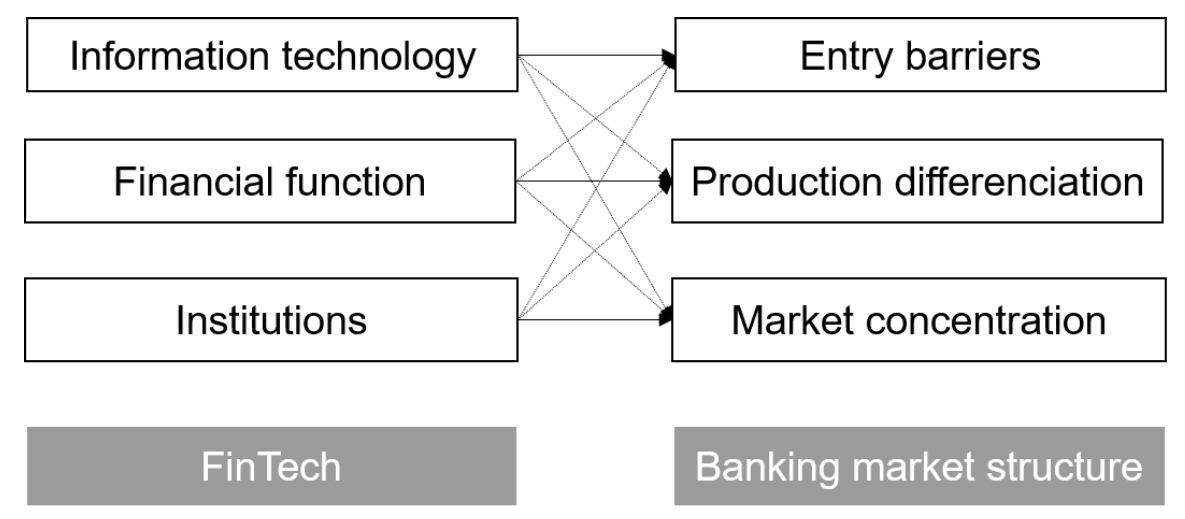

Fig.1 The impact of FinTech on the market structure of banking industry

\section{(1) the FinTech Innovative in traditional banking} institutions

Faced with the impact of FinTech and the continued decline in the growth rate of banking financial institutions and profit margins since the financial crisis in 2008, traditional banking institutions have gradually adopted FinTech to implement services reformation. By digitizing and increasing technology investment, the traditional banks can make up for the gap in financial innovation and compete with other incumbent banking institutions and new entrants such as FinTech companies. For example, domestic banks actively carry out FinTech-related businesses, set up 
business departments such as e-banking, network finance or direct banking; or establish network platforms through information technology companies to conduct financial services or support financial services (Zhu Taihui, 2018). Another example is Santander, a foreign company that stands out from the rest of its global banks and invests heavily in technology and innovative solutions. FinTech has helped traditional banks improve efficiency and quality at both technical and operational levels.

China's banking and financial institutions have further developed online banking, direct banking, mobile banking, and open banking models through digital and technological transformation, and are committed to building an open innovation ecosystem. In terms of segmentation business, banking institutions have transformed and upgraded various businesses, such as continuously expanding the electronic payment model, upgrading functions of online banking, mobile banking, ATM and smart POS; online loans are gradually approaching the Internet lending model of FinTech; The sales channels for investment and wealth management are also Internet-based and intelligent; risk control technologies are more intelligent and so on. The expansion of early banking financial institutions was limited by geographical and physical entities, and the penetration rate of Chinese commercial banks was relatively low. According to the World Bank's Iclaves, the accessibility of traditional financial services is available. As of 2015, the penetration rate of China's commercial bank branches is lower than the global average (11.6 commercial bank branches per 100,000 adults). However, the introduction of ATM It has promoted the penetration rate of financial institutions among users. The penetration rate of ATM in China is 76 ATMs per 100,000 adults.

Driven by technologies such as artificial intelligence, cloud computing, and biometrics, traditional Chinese banking institutions are striving to integrate new technologies for service transformation. According to the 2016 Banking Science and Technology Development Awards Project published in the 2017 China Financial Statistics Yearbook, 150 of the 176 winning projects are from various banking institutions, and these banking technology innovation projects involve smart banking and smart services systems, customer relationship management platforms, risk security systems, and more. In addition, major banking institutions are focusing on the deployment of intelligent outlets. Bank intelligent network technology includes business integrated tablet (including customer dashboard, advanced customer relationship management (CRM) software, digital sales module, auxiliary migration module), interactive teller machine, service terminal, video conference room, interactive welcome screen. The purpose of these technologies is to optimize business processes, improve business process efficiency, attract customer attention and achieve precise marketing. According to the China Banking Industry Service Report issued by the China Banking Association in 2018, the turnover rate of China's banking industry has reached $88.67 \%$, and the number of bank outlets has been nearly 10,000 .

\section{(2) The impact of FinTech on the market concentration of the banking industry}

Banking concentration refers to the market share occupied by banking institutions. The larger the market share of the first few institutions, the more concentrated the market is. The changes in market concentration are mainly affected by various factors, including pre-industrial concentration, barriers to entry, minimum economic scale, market size, market demand growth rate, and production differentiation. These elements can be divided into two levels of supply and demand, which affect the size and market share of institutions in the banking market. FinTech, by influencing the above factors, changes the market concentration of the banking industry. At the same time, the impact on the market concentration of banking in different bank types, regions and businesses is different.

From the supply side, technology in FinTech has changed the production methods of various institutions in the banking industry. Innovative financial products or services have changed the banking business model. Thus, traditional interbank competition, FinTech companies and traditions Competition among banking institutions has become more intense due to innovations in FinTech. On the whole, the market concentration of the banking industry has declined (Figure 2). New types of FinTech enterprises have entered the fields of payment and loans in a large amount, and the market share of traditional banking institutions has been divided, especially the segmentation of small banks' market share, showing a clear tail effect. In this regard, some 
scholars use the data of the degree of electronic banking industry to empirically test the progress of information technology in China's banking industry from 1996 to 2012, reducing the concentration of commercial banks(Jiang Yuelin, 2015). Some scholars have empirically tested that the development of Internet finance in 2006-2016 has a significant negative impact on the share of Chinese commercial banks' assets, and different types of banks have suffered different degrees of impact (Yan Xiaonan, 2018). According to the statistics of the China Banking Regulatory Commission, the concentration of banking industry is also declining. As of the end of 2017, the total number of banking financial institutions in China was 4,532, with total assets of 252.4 trillion yuan. The liabilities were 232.9 trillion yuan, an increase of $8.7 \%$ and $8.4 \%$ respectively from the beginning of the year. The growth rate of banking financial institutions also began to fall after $26 \%$ in 2009 . In terms of institution type, the scale of assets is: large commercial banks, joint-stock commercial banks, rural small and medium-sized financial institutions and urban commercial banks, accounting for $36.8 \%, 17.8 \%, 13.0 \%$ and 12.6 of the assets of banking financial institutions, respectively. \%. Looking at the concentration of the top five institutions of traditional banking financial institutions from 2003 to 2017, the market concentration of traditional banking financial institutions in China is declining. This aspect is affected by the market-oriented reform of China's banking industry. On the other hand, the rise of FinTech has promoted competition in the banking industry. Traditional banking institutions have been competed by FinTech companies, and the market share of related businesses has been affected. However, since the 21 st century, the marketization of the banking industry has continued to advance, and the extent to which FinTech has played a role in the decline in market concentration requires further empirical testing.

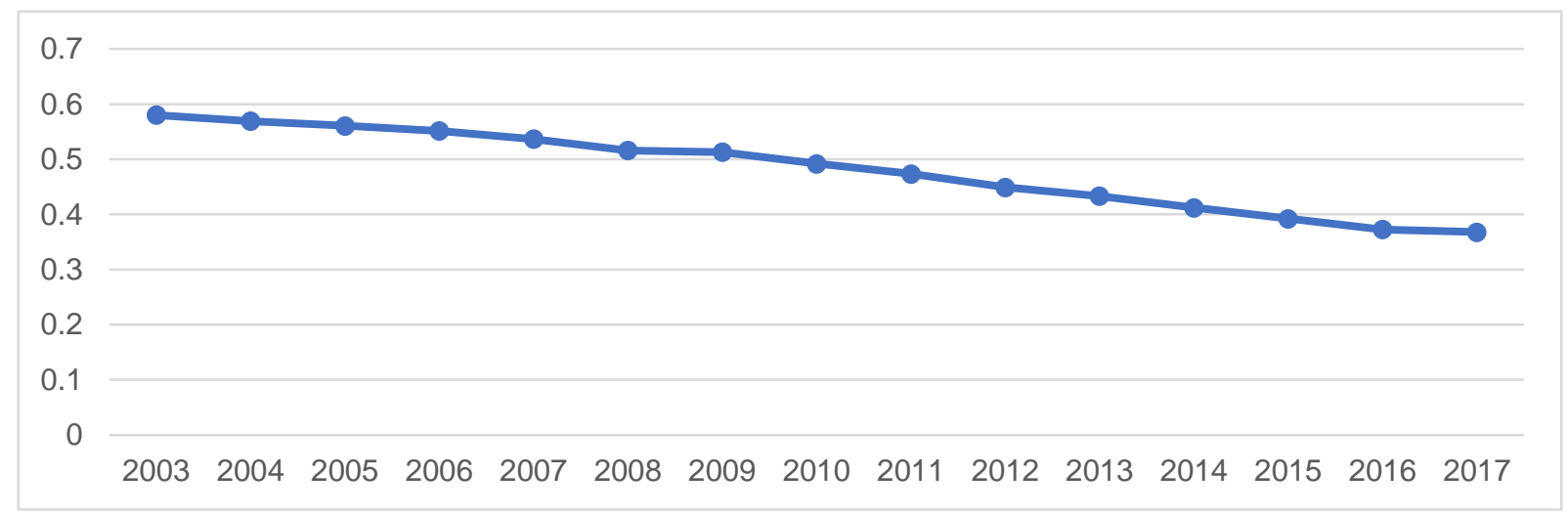

Fig.2: Total asset concentration of the top five large commercial banks in 2003-2017

However, FinTech has some cost effects including economies of scale, scope and network economy. Traditional large banks have expanded their business scope and business diversity in the process of using FinTech, and can use the original strong capital in development. Building a strong FinTech system will occupy a stronger position in the competition of FinTech. In this regard, FinTech has the role of strengthening the market share of large banking institutions and increasing the concentration of the banking market. The market concentration of FinTech enterprises is also gradually increasing, and the market structure is gradually showing a head effect. From the above analysis, FinTech has a certain stratification effect on the banking market, and the market for banking services is polarized. From the perspective of demand side, consumer demand now for banks mainly comes from information asymmetry, matching asymmetry, transaction costs and other factors in financial transactions, but FinTech can provide better solutions for these needs. It meets the needs of capital supplier and demanders whose needs are efficient, high-speed and secure financial services, and provides multi-scenario and personalized financial services. Emerging banking market players who can meet the above-mentioned needs of consumers can occupy a larger market share. From this perspective, FinTech can help reduce the market concentration of traditional banking 
institutions.

\section{(3) The impact of FinTech on entry barriers of banking industry}

The entry barriers for the banking industry mainly refer to the relationship between the incumbent enterprises participating in the banking market and the entities entering the enterprise. Banks or financial institutions that attempt to enter the banking industry not only face economic entry barriers and policy entry barriers for general enterprises, but also have unique high social barriers. The foundation of FinTech is the innovation and application of information technology. Therefore, the most obvious changes in the entry barriers of the banking industry are mainly caused by technological changes. Therefore, this part focuses on the impact of FinTech on the entry barriers of the banking economy, and policy. The barrier is not held here.There are mainly two kinds of influence of FinTech on economic barriers to entry. One kind is the change of existing economic barriers, including technical barriers and information superiority barriers. The other is the emergence of new economic barriers.

In terms of technical barriers, the technical barriers of the banking industry are mainly the incumbents' technological advantages of risk management, information processing systems, financial infrastructure, and the cost advantages of these technologies, which require a large amount of human capital and infrastructure construction which prevent new firms from entering the banking industry. However, with the development of FinTech, especially the innovation and development of technologies in information storage and processing such as cloud computing and mobile Internet, FinTech innovation enterprises usually have the characteristics of light asset, virtualization and networking, which are less subject to fixed costs, sunk costs and other constraints. Especially for FinTech innovation companies that started in large-scale technology enterprises and e-commerce enterprises, they can break through the technical barriers of the incumbents' banking from periphery, and use strong technical endowments and user resources to provide corresponding financial services to customers. For small FinTech companies, it is also possible to accumulate online users to conduct financial services through the Internet, and to quickly realize economies of scale by means of technology outsourcing. On the whole, the prosperity and development of FinTech itself and the verticalization of business have led to a reduction in the technical barriers of the banking industry.Nonethelessthere are certain differences between different banking services. For the business areas with low technical content which can be outsourced including network lending, network financing, risk control and so on, the advancement of FinTech has lowered its technical barriers; for the services with difficult and professional technology, financial innovation in science and technology has raised the barriers to entry for new businesses.

In terms of information barriers, FinTech has further reduced the barriers to information superiority in the banking industry and intensified competition in information. Traditional banking institutions rely on their product incompatibility and monopoly position, and have a very strong information advantage. It is difficult for new companies to obtain user information and provide corresponding services in a short period of time. However, in the FinTech environment, new enterprises can use the Internet, big data, artificial intelligence and other technologies to mine the basic information, transaction characteristics and risk characteristics of network users, and provide personalized financial services for individuals or enterprises. Bank institutions form competition. Therefore, FinTech has further reduced the information barriers of traditional banking.

In the new entry barriers generated by FinTech, it is mainly information access barriers. Access barriers are mainly caused by the accessibility of ports when FinTech companies seek to compete with the traditional banks in the process of entering. The control of data by traditional banks and the control of trading ports by FinTech companies. Not all interfaces are open to fair competition. For example, PSD2 requires third-party payment providers to open communication interfaces to banks, which eliminates access barriers on the one hand, but may also enable banks to obtain technical control over FinTech services and adopt fence policies for consumer data (ring-fence). ), this in turn makes FinTech innovations banned, competition reduced, and consumer choices reduced.

(4) The impact of FinTech on the production 


\section{differentiation of banking industry}

Production differentiation is mainly the different characteristics of products in the market. The product characteristics can be mainly divided into horizontal difference characteristics and vertical difference characteristics. For banks, the horizontal difference characteristics mainly refer to differentiated attributes that can satisfy consumers' different direction preferences, such as outlet location, product type, etc.; vertical difference mainly refers to the difference in satisfying consumers' same direction preferences, such as service quality, service efficiency, brand reputation, etc. The differentiation of these product characteristics or attributes is partly due to the fact that enterprises in the market are actively creating in order to gain market power, and on the other hand, they are caused by the external environment. The integration of the two aspects causes changes in the market structure, namely, market share and market concentration. Such changes are part of the analysis of market structure. In recent years, as a strong external shock factor, FinTech has changed the product characteristics and product types of the banking industry.

In terms of horizontal differentiation of banking business, the impact of FinTech has two opposite effects. On the one hand, FinTech has gradually eliminated some of the original production differentiation. The innovation of mobile Internet, Internet technology, cloud computing, artificial intelligence, etc. makes banking institutions to achieve cross-regional remote services through the establishment of internet banking, intelligent network, etc., which improving service efficiency, and thereby broadening the bank's physical business scope, increasing competition among national banking institutions. Consumers have also got instant, fast, cross-regional financial services. From this perspective, the innovation of FinTech has reduced the product differences between banks in the physical area. But on the other hand, FinTech has also increased other product differences, mainly due to production differentiation caused by technological differences, such as software differentiation. Financial institutions will also use fixed assets or intangible assets to provide diversified service products, which will increase the differentiation of banking products. This is mainly a behavioral strategy that banks generate based on the use of the scope economy. To gain greater market power under the Internet conditions and occupy a larger market share, it is necessary to develop diversified software and provide personalized Products to lock customers. Therefore, the banking industry is gradually moving towards a sales model centered on customer needs. The subjective differences in customer demand have prompted FinTech to create many different business models and service models, demonstrating significant channel differentiation preferences.

In terms of vertical production differentiation in banking, it mainly refers to product differences caused by differences in consumer preferences. In the information age, consumer demand differentiation mainly includes channel preferences, personalized preferences, reputation preferences, and price preferences. Among them, reputation preference and price preference are the more traditional and continuous preference differences of consumers. Therefore, traditional banking institutions have matured competitive means and technologies in this respect. Emerging FinTech enterprises have certain challenges in acquiring reputationsand price setting. In response to consumer channel preferences, the banking industry presents a diverse array of financial product innovations. Combining mobile devices, Internet of things and other technologies to provide financial services to consumers through multiple channels, such as through mobile devices to meet consumer demand for mobile consumer investment, IoT technology to meet consumer multi-scenario consumption and investment and financing needs. Differences in consumer channel preferences have further changed the way FinTech companies to acquire customers. In the banking industry, FinTech companies are good at acquiring customers through different channels, and establish a simple, convenient, personalized, transparent and differentiated customer experience. In response to individualized differences among consumers, data technology uses user big data to classify users, thereby providing products with differentiated quality or differentiated prices, and gaining competitive advantage among different customer groups. But this will lead to unfair practices such as user exclusion and price discrimination, and damage consumer welfare. This further raises corresponding requirements for consumer protection.

III. REGULATION PROBLEMS OF CHINA'S BANKING INDUSTRY UNDER FINTECH 
With the influence ofFinTech, China's banking industry has developed rapidly. However, there are a series of problems in the development process which relating to banking regulation. These issues are related to the stability of the financial system, the guarantee of consumer rights and the fairness of market development. Based on the analysis of changes in the banking market structure in the previous section, this part analyzes and summarizes the problems existing in the banking industry under the influence ofFinTech, and raises the challenges faced by the banking industry.

(1) System complexity of network information security issues

FinTech has the attribute characteristics of information technology, so there are risk problems such as technical risks, operational risks, and technical systemic risks. These risks can be summarized as network and information security issues. Information security is the basis of ensuring the innovation and development of internet finance. In addition to the traditional Internet technology risks, it also faces the security risks of new situations, new technologies and new formats. First, the security mechanisms for supporting new technologies such asbig data, cloud computing, and artificial intelligence in the banking industry are not perfect. Secondly, new forms of internet finance such as third-party payment and P2P are still in their infancy, and the security management of FinTech enterprises themselves is still in the stage of exploration and discovery, which is prone to unexpected risks. Finally, information technology such as the internet has made the connection between banksand FinTech companies closer, and information infrastructure has become an important part of the banking financial infrastructure, so that the network security problems of information infrastructure will become an important factors of system risks.

Therefore, while the rapid development of internet finance business, the prominent network and information security issues have become an important aspect that hinders the healthy and stable development of internet finance. At the same time, the application of FinTech has increased the relevance of financial institutions and the complexity of the financial system, making these risks more sensitive and contagious. Therefore, with the application of emerging information technologies, people should identify and supervise risks more quickly and accurately technically.

(2) Network contagion of banking concentration risk

FinTech has made the inter-institutional correlation in the banking industry close and complex. With the change of banking concentration, the performance characteristics of banking concentration have changed accordingly, showing significant network contagion. First of all, the high embedding of FinTech in the banking industry reflects the dependence of banking financial institutions on information network technologies and equipment. The linkages between banking institutions are very close. Therefore, the outbreak and spread of concentration risks will be more immediate due to the network connection. For the sake of speed. Secondly, FinTech enterprises are gradually showing "head effect", and the market concentration is increasing. The financial fragility of a single large-scale FinTech enterprise will affect the stability of the entire financial industry. Recently, the national regulatory policy has adopted systemically important financial institutions as the focus of monitoring risks, and some large FinTech companies have also been listed as systemically important financial institutions. Finally, FinTech companies at the head of the market usually have stronger economies of scale and scope, that is, they are more inclined to cross-industry operations, product bundle sales, and vertical integration. Although most of the FinTech companies' business targets are "long tail" consumers in the market and even SME institutional users, as a FinTech company with a high market share, it usually has a large number of consumer groups to achieve economies of scale and scope. Therefore, once consumer confidence fluctuates or declines greatly, especially under the information network organization, consumers mostly have multi-homing phenomenon, so it will affect other platforms to which consumers belong, which will lead to regional or large-scale systemic risks. On the whole, the concentration risk or the concentration risk of the organization presents the characteristics of cross-industry, cross-sectoral cross-over, and network infection.

(3) The problems of banking monopoly and competition On the one hand, FinTech has changed the original barriers to entry, and on the other hand, it has created new barriers to entry. The banking market has shown a situation of monopoly strengthening and excessive competition. The barriers to entry of monopoly power by traditional banking 
institutions have been broken by FinTech. A large number of FinTech enterprises have entered various areas of the banking market, but there are differences in the degree of entry in different business areas, and the problems that arise are also different. For business areas with high barriers to entry, FinTech will accelerate monopoly. This is mainly because of the increase in the constraints of technological monopoly, data monopoly, and interface monopoly under the competition of FinTech innovation, which makes the cost of entering new enterprises rise, thereby restricting entry and weakening competition.

For business areas with low entry barriers, FinTech has intensified the level of competition in this area. At present, some FinTech-related businesses with low technical requirements have achieved full specialization and segmentation, such as consumer finance, personal loans, and retail banking, and the barriers to entry in these links have decreased. The decentralized market structure enables small FinTech companies to easily enter and form economies of scale, thereby increasing market competition. However, such institutions can easily circumvent the laws and regulations of financial supervision, resulting in regulatory arbitrage, illegal speculation, and "beating and running". Especially in the case of China's financial regulatory system construction still needs to be improved, it implies extremely high financial risks. Since the development of the P2P field in 2013, as of 2018, there have been bubble bursting of different sizes $\mathrm{P} 2 \mathrm{P}$ platforms, of which 2016 reached the peak, with a total of 1,741 problem platforms. On the whole, the development of $\mathrm{P} 2 \mathrm{P}$ is mainly the development of business model, and the requirements for technology are relatively low. The financing of funds can be realized by constructing a platform that conforms to the regulatory qualifications. These institutions lack a professional and complete credit management system, and it is difficult to accurately identify the qualifications of individual users, and there is a very high credit recognition cost. In order to achieve rapid market occupation, expand user share, speculative cash, high interest rates, false targets, self-containment, demolition, and just against the problems have occurred. Regulators face huge regulatory costs in the market where there are a large number of competitive entities. Therefore, for business areas with low barriers to entry, access regulation should be strengthened to avoid excessive supervision.

(4) the digitalization of unfair competition and its welfare damage

Under the influence of FinTech, the way of inter-institutional competition in the banking industry has become more informational and intelligent. Some unfair competition and anti-competitive behavior have also changed their performance. On the one hand, financial institutions use artificial intelligence, big data and other technologies to analyze the consumption and credit data of individual users, and provide financial products or services with different price scores and different tastes for users with different credit scores and preferences. However, the algorithm technology behind it can also achieve unfair competition behaviors such as monopoly collusion, price discrimination, scene fraud, and the difficulty of definition and recognition becomes more and more. The existing regulations cannot identify and detect this aspect.

On the other hand, with the virtualization of organizations, the traditional differentiated competition relying on physical outlets has gradually faded. Many financial services are provided through the network, and the informationization of service methods and product models has further contributed to the emergence of illegal competition. And the form is more subtle. For example, some FinTech companies or financial institutions through the network to achieve illegal sales, leak customer information, kidnap bank credit, cash withdrawal difficulties, roll money and other misconduct, consumers are difficult to identify in advance. These have caused damage to the stability of the financial market and consumer rights. In this aspect of regulation, there have been provisions that high-risk and high-yield financial products should strictly enforce investor suitability standards and strengthen information disclosure requirements. It is clearly clarified that Internet financial institutions must not provide high-return financial products to customers through explicit subsidies, cross-subsidies or other client funds in a dominant or implicit manner. Highly concerned about the commitment or actual income level of Internet financial products is significantly higher than the project rate of return or industry level. The China Internet Finance Association established an expert review committee to urge relevant departments to evaluate and 
determine the unfair competition behavior of Internet finance, and handed the results to relevant departments as a basis for punishment.

\section{(5) Ambiguity ofBanking IndustryMarket Boundary}

For traditional financial services, the boundaries between various types of business are clear, and the main responsibility is clear. Although some financial institutions adopt a comprehensive mixed operation, they can clearly distinguish various business entities. However, in the Internet environment, usually a single business requires multiple legal divisions of labor to complete (IMF Task Force and Li Lili, 2017). The financial services finally obtained by financial consumers tend to appear as a single result, and this result may be formed by the division of labor of multiple legal entities and undergoing a complex integration process (IMF Task Force and Li Lili, 2017). For example, P2P network lending needs to break through the limitations of traditional geography, karma and other acquaintances through online credit analysis, online operation and third-party guarantees, online and offline integration, etc., and realize the supply and demand docking between strangers (Li Jizun, 2015).

\section{(6) Information Islanding within the Banking}

\section{Institutions}

With the influence ofFinTech, the differentiated advantages of traditional banking institutions relying on competition are gradually weakened, such as geographical advantages and dot density. At present, various banking institutions have launched their own online services and mobile services, providing differentiated network services based on technology to attract and lock customers. Moreover, the same banking institution will develop different types of service platforms according to different types of products, such as credit card business, savings business, and wealth management business, which have different software APPs for customers to use. These phenomena are usually continuation of the organizational model of the original banking institutions, resulting in the use of services in online services to form silos of information. This island exists not only between banks but also between various businesses of the same bank.

\section{CONCLUSIONS}

This paper analyzes the impact of FinTech on the market structure of banking industry and the raising regulation problems of banks in the market structure reform of banking industry. These problems have created enormous challenges to the existing Chinese regulatory system. To address these issues, we have gained some inspiration and proposed corresponding regulatory recommendations.

First, the regulation method should be more scientific, intelligent and international, and then furtherly establish a standardized FinTech standard system. FinTech has given the banking industry a higher technological value and more technological innovations, which has made banking risk issues more technically. Therefore, the corresponding regulatory approach must also have innovative technical tools and corresponding technical governance frameworks, which can intelligently implement real-time supervision. At the same time, information technologies such as the Internet, cloud computing, and big data have greatly reduced the geographical restrictions of financial services. They can not only operate across countries in a country, but also operate across countries around the world. Therefore, these technologies are the core elements of FinTech. There is a need for a regulatory system with an international regulatory approach. At the same time, a FinTech technical standards system should be constructed. Government departments and regulatory agencies need to coordinate and cooperate to develop interoperable and coordinated technical standards to achieve a fair competition envioronment. The technical standards system includes data, information, business and other aspects, such as technical standards for market access and exit, financial data standards, and information security protection standards. On the one hand, by determining the standard system, it is able to regulate the operation of the FinTech industry, while at the same time promoting information sharing and reducing the data gap, and deepening coordination and cooperation between different regulation administrations. On the other hand, technical standards with interoperability and coordination can promote cooperationof industry entities, and also facilitate cross-departmental collaboration between regulatory authorities, government departments and industries, thereby promoting innovation in FinTech and reducing potential risks in the industry.

Second, build a regulatory model that matches the business model of Fintech. The main purpose of constructing a 
regulatory model that matches the business model is to compensate for regulatory gaps. The rapid development of FinTech has produced a large number of start-up FinTech enterprises, and the head effect has become increasingly obvious. At the same time, it has profoundly changed the business model of traditional banking institutions. However, FinTech companies have also shown phenomena of barbaric growth and lack of effective regulatory guidance. Therefore, on the one hand, it is necessary to provide a regulatory infrastructure suitable for the current banking business model, such as a comprehensive credit evaluation system, a systemic risk monitoring system, and regulatory regulations for mixed operations. On the other hand, it should be combined with the characteristics of FinTech and formulate targeted regulatory policies. For example, from the perspective of market concentration, it is recommended to incorporate cross-industry and cross-business concentration risk factors into the systemic risk supervision framework. In terms of access regulation, we should focus on coordinating competition regulation and risk supervision policies. For production differentiation competition, it is recommended to build a competition supervision policy based on supervision technology, and supervise unfair competition caused by FinTech.

Third, on the regulatory framework, a reasonable coordination mechanism between banking competition supervision and other financial regulatory agencies should be established. FinTech has changed the barriers to entry and production differentiation in the banking industry, so the market competition has changed. Banking competition supervision should fully consider the characteristics of FinTech, and be able to scientifically identify and prevent monopolistic problems and competitive chaos brought about by technology and digitalization. The financial regulatory policies should not only ensure the prevention of financial risks and to protect the interests of financial consumers, but also ensure a fair competition environment in the banking market to achieve financial stability. However, neither the existing financial regulatory policy nor the existing competition policy can achieve the goal by one kind of policies, for there is a trade-off between the competition fairness and financial stability. Therefore, it is necessary to construct a coordinated governance structure between financial supervision and competition policy to achieve stability and fairness in the banking market. For example, building an open and shared banking service system to promote fair competition in the banking market. Open sharing mainly refers to the open sharing of data information, such as consumer credit information. For financial service providers, an open banking system can narrow the information gap, reduce moral hazard, and improve the stability of the banking system. For consumers, an open banking system enables them to call their own consumption data among banks, reduce their conversion costs, and increase the utilization of bank resources.

\section{REFERENCES}

[1] Alt, Beck \& Smits (2018), FinTech and the Transformation of the Financial Industry. Electronic Markets, 28(3), 235-243.

[2] Arner, Barberis\& Buckley (2016), The Evolution of Fintech: A New Post-Crisis Paradigm? Georgetown Journal of International Law, 47, 1271-1319.

[3] Arner, Barberis\& Buckley (2017), FinTech, RegTech, and the Reconceptualization of Financial Regulation. Northwestern Journal of International Law \& Business, 37(3), 371-413.

[4] Bettinger (1972), FINTECH: A Series of 40 Time Shared Models Used at Manufacturers Hanover Trust Company. Interfaces, 2(4), 62-63.

[5] Gai, Qiu\& Sun (2018), A Survey On FinTech. Journal of Network and Computer Applications, 103, 262-273.

[6] Imf Group, Li Lili (2017), "Finance Technology, Regulatory Framework and Reform of Financial Services Industry", New Finance, 10, 8-14.

[7] Saksonova\& Kuzmina-Merlino (2017), Fintech as Financial Innovation - the Possibilities and Problems of Implementation. European Research Studies, 20(3A), 961-973.

[8] Jiang Yuelin (2015) Network Scale, Technology Progress and Banking Competition, Master Dissertation, Shandong University.

[9] Yan Xiaonan(2018)Research on the Impact of Internet Finance on the Market Structure and Performance of China's Commercial Banks, Tianjin University of Commerce, .

[10] Zhu Taihui (2018), A Comprehensive Analysis Framework for the Evolution of Fintech in China, Financial Regulatory Research, 01,55-67.

[11] Li Jizun (2015), Thinking about Internet Finance, Management World, 07, 1-7. 